\title{
Conseil juridique
}

\section{(8) 82808}

Droit du travail

Statuts

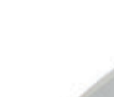

Création SA / SARL
Convention

d'actionnaires

\section{年}

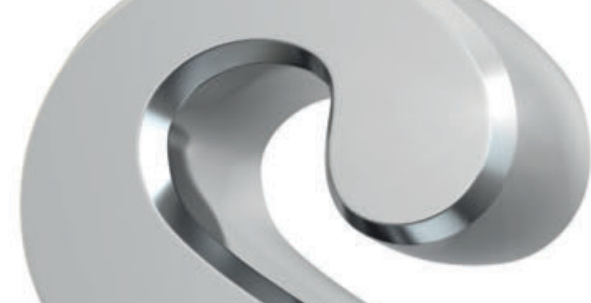

Contrat de reprise de cabinet

\section{Contrat de bail}

\section{Droit fiscal / TVA}

\section{Contrat d'utilisation de l'infrastructure}

En tant que prestataire de services du corps médical, nous proposons

- Préparation et contrôle de contrats et conventions par des juristes en collaboration avec des économistes

- Réponses à vos questions en lien avec le droit du travail et le droit fiscal (y c. TVA)

- Élaboration de statuts pour personnes morales et de règlements du personnel ou de direction

CONSEIL JURIDIQUE

\section{DFMHSERVICES}

Vous pouvez prendre contact avec nous sans aucune obligation par téléphone ou courrier électronique ou en nous retournant le talon-réponse par fax ou par la Poste. Nous vous contacterons.

Prénom / nom

Adresse

NPA / lieu

Téléphone privé / prof.

Atteignable de préférence vers

\section{CONSULTING}

\section{FMH Consulting Services AG}

Burghöhe 1, 6208 Oberkirch

Tél. 0419250077 - Fax 0419250067

mail@fmhconsulting.ch - www.fmhservices.ch 